\title{
Retraction
}

\section{Retracted: Occluded Face Recognition Based on Double Layers Module Sparsity Difference}

\author{
Advances in Electronics \\ Received 31 December 2014; Accepted 31 December 2014 \\ Copyright (C) 2015 Advances in Electronics. This is an open access article distributed under the Creative Commons Attribution \\ License, which permits unrestricted use, distribution, and reproduction in any medium, provided the original work is properly \\ cited.
}

The paper titled "Occluded Face Recognition Based on Double Layers Module Sparsity Difference" [1], published in Advances in Electronics, has been retracted, upon the authors' request, as they found a bug in the Matlab code used in this study which makes the results incorrect.

\section{References}

[1] S. Zhao and Z. Hu, "Occluded face recognition based on double layers module sparsity difference," Advances in Electronics, vol. 2014, Article ID 687827, 6 pages, 2014. 

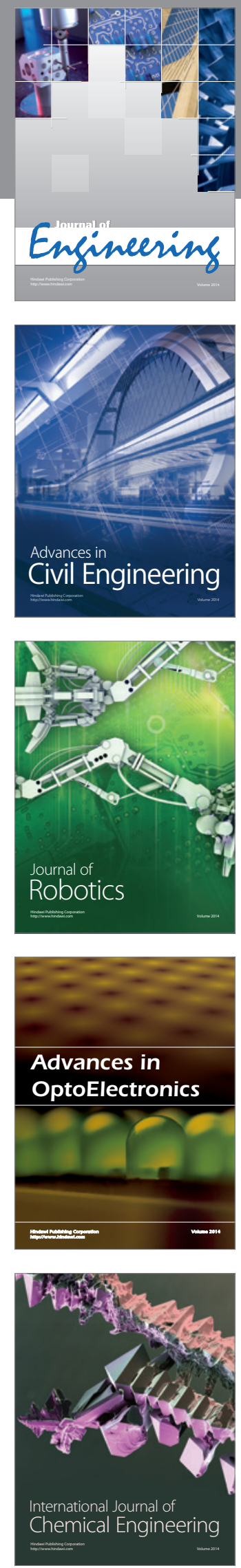

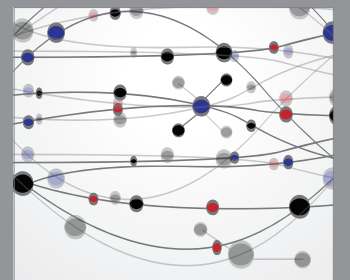

The Scientific World Journal
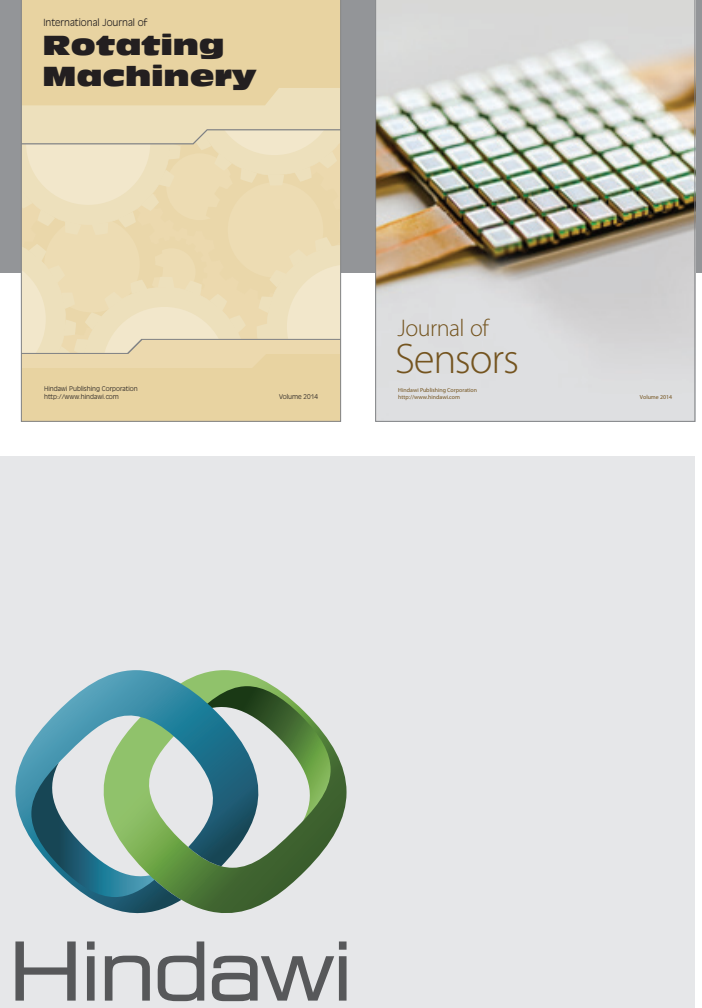

Submit your manuscripts at http://www.hindawi.com
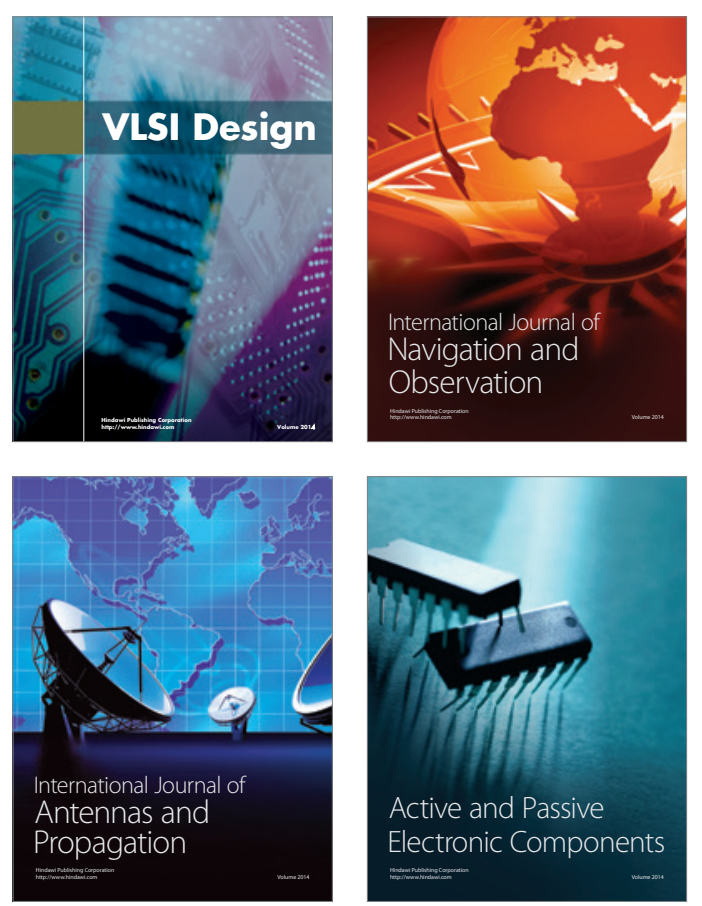
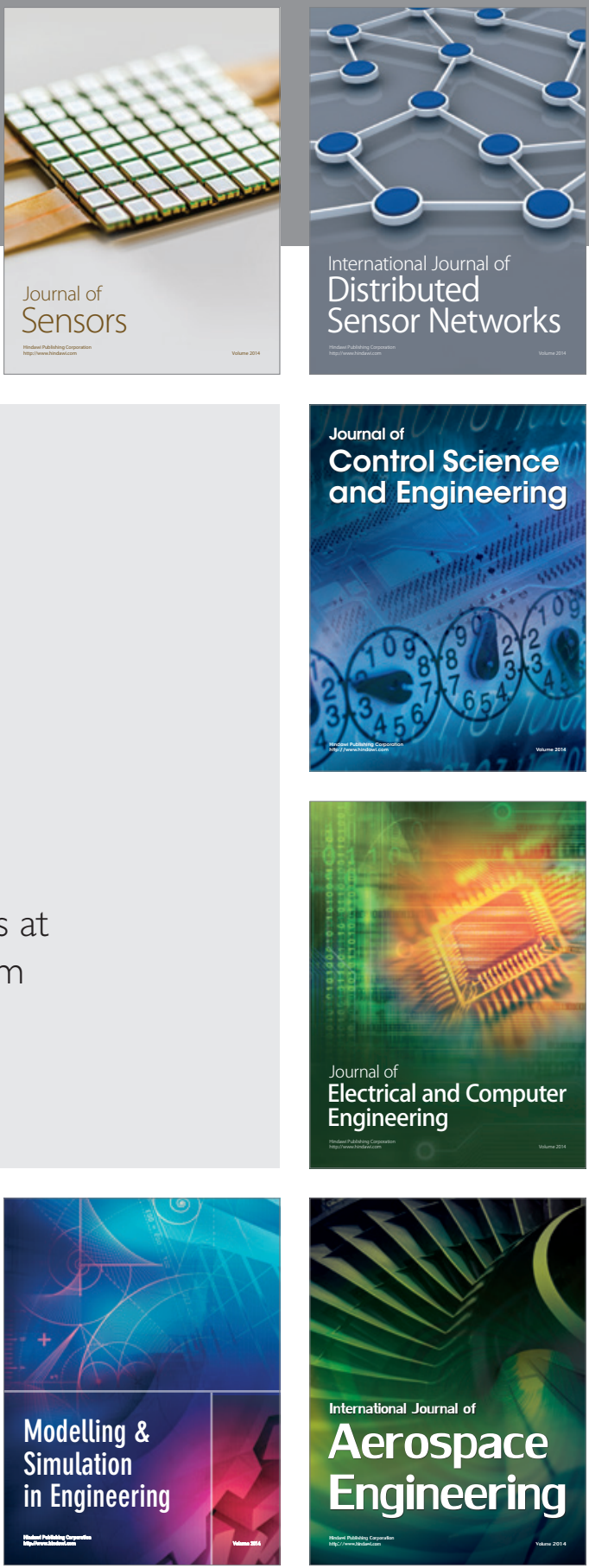

Journal of

Control Science

and Engineering
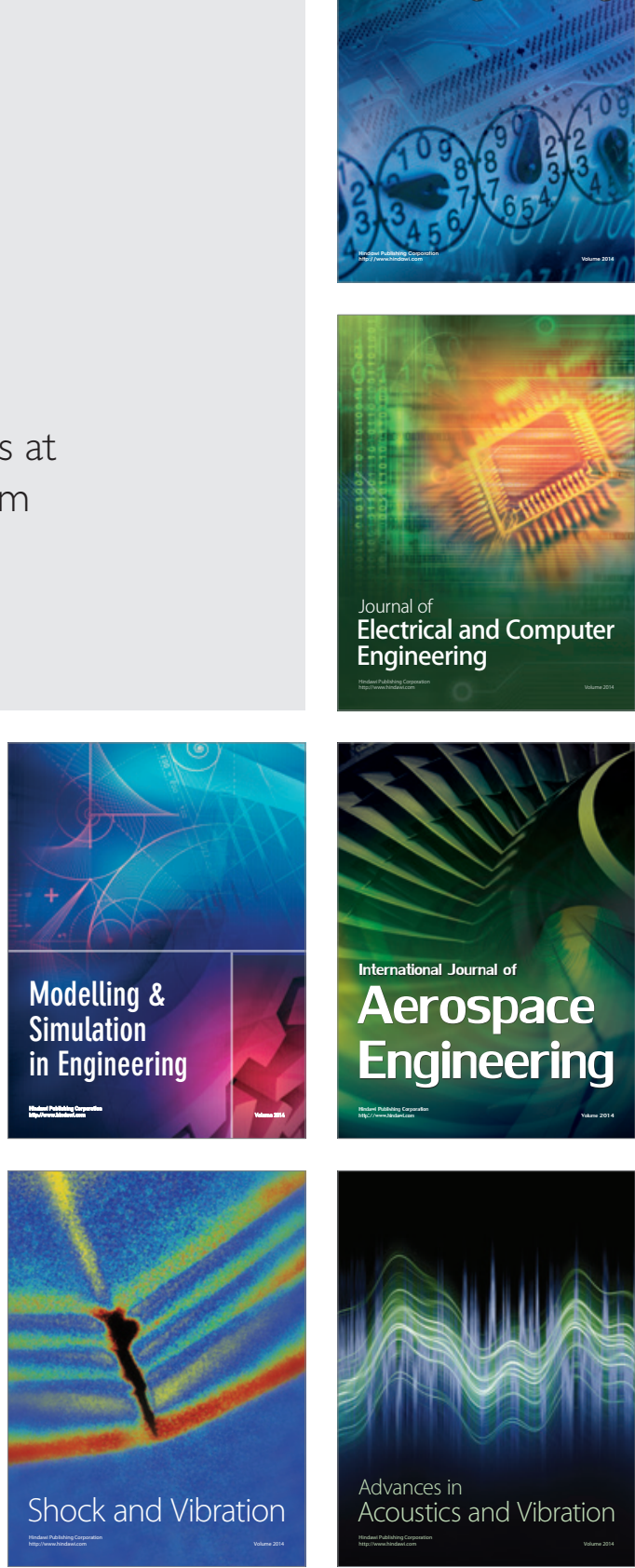